\title{
Central body fat distribution indices in Thai preschool children*
}

\author{
Uruwan Yamborisut ${ }^{1}$, Naoko Sakamoto ${ }^{2}$, Piyanuch Visetchart ${ }^{1}$, Kraisid Tontisirin ${ }^{3}$ \\ ${ }^{1}$ Human Nutrition Division, Institute of Nutrition, Mahidol University, Nakhon Pathom, Thailand \\ ${ }^{2}$ National Research Institute for Child Health and Development, Tokyo, Japan \\ ${ }^{3}$ Senior Nutrition Consultant, Institute of Nutrition, Mahidol University, Nakhon Pathom, Thailand \\ Email:nuuyb@mahidol.ac.th
}

Received 30 September 2011; revised 10 January 2012; accepted 30 January 2012

\begin{abstract}
Background: Central obesity is associated with adverse health outcomes. This study aimed to determine the characteristics of central body fat distribution in Thai preschool children and to examine factors that could influence on body fat distribution of children. Methods: The total 811, 5 - 6 years old children were randomly sampled from 9 primary schools in Saraburi province. Body weight and height were measured in each child. Waist circumference (WC) was measured at the umbilicus level and hip circumference (HC) at the level yielding maximum circumference over buttock. Subcutaneous skinfold was measured on biceps, triceps, subscapular, supra-iliac and abdominal regions. Total body fat (TBF) was measured with bioelectrical impedance analyzer. Results: Mean values of WC, waist-to-hip ratio (WHR) and waist-to-height ratio (WHtR) of boys were not different from those of girls. Even though trunk skinfolds of both genders were similar, girls tended to have slightly greater biceps, triceps and subscapular skinfolds than boys. Strongly positive correlation was found between WC, WHtR, trunk skinfold and child's BMI $(p=0.01)$ as well as between WC, WHtR, trunk skinfold and child's TBF $(p=0.01)$. Multiple regression analysis demonstrated, in both genders, that BMI, age and TBF were strongly associated with WC (Adjusted $\mathbf{R}^{2}$ $0.92-0.93$ ) and WHtR (Adjusted $R^{2} 0.90-0.92$ ) and that BMI and TBF were strongly associated with trunk skinfold (Adjusted $R^{2} 0.88$ - 0.89). The association between WHR and TBF for boys and between WHR and BMI for girls were found to be weak in this study. Conclusion: No gender difference in body fat distribution indices was found in Thai preschool children. Change in central body fat distribution of children could be strongly influenced by their changes in age, BMI and TBF.
\end{abstract}

\footnotetext{
${ }^{*}$ The authors declare no conflict of interest.
}

Keywords: Central Body Fat Distribution; Thai; Preschool Children; Waist Circumference; Subcutaneous Skinfold

\section{INTRODUCTION}

The prevalence of childhood obesity has strikingly increased in many countries during the past decades [1,2]. Tracking of obesity in children is generally performed using body mass index (BMI). However, the limitation of $\mathrm{BMI}$ is that it does not distinguish obesity due to excess fat mass from the obesity due to excess lean body mass [3]. The change in body fat distribution in addition to the increased total body fat, has an importance as predictor of cardiovascular risk factor in children [4,5]. Evidence shows that gender difference in fat distribution has been observed in adolescents [6-8] and one study reported the sexual dimorphism of body fat distribution in prepubertal children [9]. Studies also demonstrated ethnic difference in fat distribution in prepubertal children [10-12] and in pubertal children [13]. In children, body fat distribution could be assessed using various anthropometric indices such as waist circumference (WC) alone [14], waist-to-height ratio (WHtR) [15] and skinfold ratio [16]. The use of WC and WHtR provides the advantage in that the indexes are good predictors of intra-abdominal fat deposition and are related to the development of cardiovascular risk factor [17-19] Previous reports have also indicated the trunk skinfold as the sensitive tool to detect metabolic abnormalities in children and adolescents $[4,20]$. Nevertheless, less information was known on the determinant factors that could influence on change in body fat distribution in terms of anthropometric and body composition measures.

In Thailand, the rapid change in national economic during past 20 years has had the impact on nutrition transition and that problem of over-nutrition in children persistently exist in different areas. In 2009, data from the National Health Examination Survey in 3015, 1 - 5 
year-old children from 21 provinces in Thailand indicated that the prevalence of the overweight and obesity in children were $3.5 \%$ and $8.5 \%$, respectively [21] and the obesity rate among young children in urban area such as; Bangkok city, was as high as $14.9 \%$. Since data on the characteristics of central body fat distribution in young Thai children is not available. The aims of this study was 1) to determine gender difference in central body fat distribution of young Thai children and 2) to examine the determinant factors that influence on body fat distribution indices of children.

\section{METHODS}

\subsection{Study Subjects}

This cross-sectional study was conducted in Saraburi, a province located in the central part of Thailand, during July-September 2008.The province was $113 \mathrm{~km}$. away from Bangkok. The city comprises of 13 districts. Twostage stratified sampling technique was applied to recruit target children. Approximately 30\% of total 13 districts was sampled and that Mueang, Phra Phuttabat, Kaeng Khoi and Nong Khae were sampled as the representative districts. School selection was based on school zone located in these 4 districts. The large school size $(\geq 600$ pupils) was subsequently sampled and that target children from 9 primary schools were recruited in the study. Subjects were 5 - 6 year old children, whose families were residing in the municipal areas of Saraburi province. They were studying in the kindergartens grade 1 and 2 . Children who were under- or over-nutrition resulting from pathological disease or receiving any medication were excluded from the study. Prior to the beginning of the study, formal letter were sent to school directors and children's parents for asking permission. Written consent forms were also obtained from all parents. The study design was approved by the Mahidol University Institutional Review Board (MU-IRB) (COA. No. MU-IRB2008/050.1507).

\subsection{Anthropometric Measurement}

Anthropometric measurements were performed in all children. Body weight of each child was measured using digital weighing scale (CAMRY ${ }^{\mathrm{R}}$; Model EB-6571, Nanjing; capacity 0 - $150 \mathrm{~kg}$ ) to the nearest $100 \mathrm{~g}$. To check for the reliable data, weighing balance was calibrated with standard weight before measurement. Standing height of the child was measured with stadiometer (Stanley$\mathrm{Mabo}^{\mathrm{R}}$, Poissy, France). The subjects stood without shoes, feet together and buttock in contact with the wall. The head-bar was lowered to attach the crown of subject's head and height was measured to the nearest $0.1 \mathrm{~cm}$. Body mass index was calculated as the value of child's body weight divided by squared height $\left(\mathrm{kg} / \mathrm{m}^{2}\right)$. Waist circumference (WC) was measured at the umbilicus level using non-elastic tape. Hip circumference (HC) was measured at the level yielding maximum circumference over the buttock. Waist-to-hip ratio (WHR) was calculated by WC divided by HC value. Waist-to-height ratio was calculated by WC divided by height value. Measurement of subcutaneous skinfolds at various sites were also performed using skinfold calipers (Holtain Ltd, Crymych, UK). Triceps skinfold was measured on the upper right arm, mid-way between acromiom process of scapular and tip of ulna. Biceps skinfold was measured at the anterior aspect of right arm at the same level as triceps. Subcsapular skinfold was measured $1 \mathrm{~cm}$ inferior to the inferior angle of the scapular. Suprailiac skinfold was measured immediately superior to the iliac crest as the oblique skinfold. The abdominal skinfold was at $3 \mathrm{~cm}$ lateral to the umbilicus and $1 \mathrm{~cm}$ inferior to it. Measurement of skinfold at each anatomical site was performed twice and the average value was estimated. Percentage of trunk/total skinfold was calculated as sum of subscapular, abdominal and supra-iliac skinfolds divided by total skinfolds $\times 100$. Measurement of total body fat (TBF) of children was done using tetra-polar bioelectrical impedance analyzer (Tanita ${ }^{\mathrm{R}}$; InnerScan, Model BC-545, Tokyo, Japan). After stepping on the platform, subject was instructed to hold the electrodes with both hand grips and arms straight down for 1 - 2 minutes until body fat was determined.

\subsection{Statistical Analysis}

All anthropometric data were analyzed by Statistical Package for Social Science (SPSS, version 18, Chicago, IL, USA). Anthropometric variables were presented as mean \pm standard deviation (SD). Significant mean difference in anthropometric variables between genders was analyzed using unpaired student's $t$-test. Pearson correlation coefficient was applied to examine the relationship between central body fat distribution indices and anthropometric measures of children. Multiple linear regression using stepwise method was used to determine factors that influenced on body fat distribution indices of children.

\section{RESULTS}

All data analysis was performed on total 811 children; 406 boys and 405 girls. The characteristics of children are shown in Table 1. Mean age of boys was similar to that of girls. Boys had slightly greater BMI than girls. Regarding anthropometric parameters, it was found that mean values of WC, HC, WHR and WHtR of boys were not significantly different from those of girls. Although there was no mean difference in trunk skinfold between 
Table 1. Anthropometric characteristics of children.

\begin{tabular}{lcc}
\hline \multicolumn{1}{c}{ Anthropometric variables } & $\begin{array}{c}\text { Boys } \\
(\mathbf{n}=\mathbf{4 0 6})\end{array}$ & $\begin{array}{c}\text { Girls } \\
(\mathbf{n}=\mathbf{4 0 5})\end{array}$ \\
\hline Age (y) & $5.5(0.36)$ & $5.6(0.36)$ \\
Weight (kg) & $20.4(4.9)$ & $19.8(5.3)$ \\
Height (cm) & $111.9(5.3)$ & $111.4(5.6)$ \\
BMI (kg/m²) & $16.2(2.9)$ & $15.7(2.8)^{*}$ \\
Waist circumference (WC, cm) & $54.2(7.6)$ & $53.8(7.4)$ \\
Hip circumference (HC, cm) & $57.3(6.5)$ & $57.3(6.6)$ \\
Waist-to-hip ratio (WHR) & $0.94(0.04)$ & $0.94(0.04)$ \\
Waist-to-height ratio (WHtR) & $0.48(0.06)$ & $0.48(0.05)$ \\
Subcutaneous skinfolds Biceps (mm) & $5.6(2.6)$ & $6.1(2.6)^{*}$ \\
Triceps (mm) & $9.2(3.9)$ & $9.8(3.7)^{*}$ \\
Subscapular (mm) & $6.4(3.7)$ & $6.9(3.6)^{*}$ \\
Supra-iliac (mm) & $5.8(4.3)$ & $6.3(4.1)$ \\
Abdominal (mm) & $7.2(4.9)$ & $7.6(4.5)$ \\
Trunk skinfold ${ }^{\dagger}$ (mm) & $19.4 \quad(12.5)$ & $20.8(11.4)$ \\
\% trunk/total skinfold ${ }^{\ddagger}$ & $55.1(4.6)$ & $55.5(4.4)$ \\
\% Total body fat & $14.0(8.2)$ & $14.4(6.4)$ \\
\hline
\end{tabular}

Values were mean (SD); ${ }^{\dagger}$ Subscapular + supra-iliac +abdominal skinfolds; ¥Subscapular + suprailiac + abdominal skinfolds/biceps + triceps + subscapular + supra-iliac + abdominal skinfolds $\times 100$; ${ }^{*}$ Significantly different from boys at $\mathrm{p}<0.05$, by unpaired student $t$-test.

boys and girls, however, girls had significantly greater values of biceps, triceps and subscapular skinfolds $(\mathrm{p}<$ 0.05 ) than those of boys, Mean TBF of boys was similar to that of girls. Table 2 demonstrates the relationship of fat distribution indices to anthropometric variables of both genders. It was shown that child's body weight strongly correlated with WC, WHtR and trunk skinfold whereas the correlation between child's height and WC, WHtR and trunk skinfold were found to be weaker. The child's BMI strongly correlated with WC $(\mathrm{r}=0.96, \mathrm{p}=$ $0.01)$, WHtR $(r=0.94-0.95, p=0.01)$ and trunk skinfold $(r=0.92-0.93, p=0.01)$. Similarly, percentage TBF of both genders strongly correlated with WC, WHtR and trunk skinfold. By multiple regression analysis, Table 3 demonstrated that factors that were associated with change in WC and WHtR of both genders were BMI, TBF and the age of the child (Adjusted $\mathrm{R}^{2} 0.92$ 0.93 for WC and adjusted $\mathrm{R}^{2} 0.90$ - 0.92 for WHtR). In addition, trunk skinfold could also be predicted by TBF and BMI but not the age of the child. (Adjusted $\mathrm{R}^{2} 0.88$ 0.89). Although WHR of boys could be predicted by TBF and age and WHR of girls predicted by BMI, however, the predictive value was smaller (Adjusted $R^{2} 0.22$ 0.31 ) compared to those of WC, WHtR and trunk skin- fold.

\section{DISCUSSION}

The main findings of this study was the characteristic of central body fat distribution in young Thai children. Our results showed no significant mean difference in WC, WHR and WHtR between boys and girls. This could be explained by the fact that central fat patterning does not occur in prepubertal period. Former studies [22,23] demonstrated that WC increased with age in both genders and the difference in WC was significant after pu berty. Regarding WHR parameter, previous studies in European children indicated that sexual dimorphism in fat distribution as indicated by WHR was present in 5 - 7 year old children $[9,24]$ but our results showed no difference in WHR between genders. This might be due to the influence of ethnic difference that conveys to the difference in body size of the growing child. The effect of ethnic difference on body fat distribution has been investigated in young children. He et al. [11] demonstrated that among girls, Asian had generally lower extremities and gynoid fat than Caucasians and African-American whereas among boys, Asian had lower extremity fat by dual-energy X-ray absorptiometry (DXA) than Caucasian but greater gynoid fat by skinfolds than African-American. The fact that mean percentage of TBF of boys was similar to that of girls found in our study was consistent with previous study which demonstrated that gender difference in fat mass is negligible before 5 6 years of age [25]. Then the increase in fat mass was found more in girls than in boys through adolescence period and boys have an increase in muscle mass and central adiposity due to the secretion of testosterone hormone whereas girls have increased body fat, primarily at gluteal site due to estradiol [26]. Several studies indicated that sexual dimorphism of body fat distribution had been reported during puberty $[7,8,27]$ and one study in young children [9].

The strongly positive correlation between WC, WHtR, trunk skinfold and BMI and between WC, WHtR, trunk skinfold and TBF in both genders found in our study suggested that these body fat distribution indices could be alternatively used as screening tools to detect obesity in children. Glaber et al. [28] reported that BMI and WC performed well in detecting excess body fat in 7 - 14 year old children. Similarly, Hubert et al. [29] showed that WC and WHtR were sensitive indicators used for obesity screening in prepubertal children. Our results also showed that change in WC of children could be strongly predicted by child factors; i.e., age, BMI, and TBF. Daniels et al. [14] demonstrated that child's age was one important determinant of fat distribution as indicated by change in WC. A few studies reported the significantly 
Table 2. Pearson correlation coefficient between central body fat distribution and anthropometric indices of children.

\begin{tabular}{ccccccccc}
\hline Variables & \multicolumn{3}{c}{ Boys (n= 406) } & \multicolumn{3}{c}{ Girls (n = 405) } \\
\hline \multirow{2}{*}{ Body weight } & $0.96^{*}$ & $0.44^{*}$ & $0.84^{*}$ & $0.89^{*}$ & $0.96^{*}$ & $0.39^{*}$ & $0.84^{*}$ & $0.89^{*}$ \\
Height & $0.57^{*}$ & 0.03 & $0.28^{*}$ & $0.44^{*}$ & $0.66^{*}$ & 0.08 & $0.36^{*}$ & $0.52^{*}$ \\
BMI & $0.96^{*}$ & $0.54^{*}$ & $0.95^{*}$ & $0.92^{*}$ & $0.96^{*}$ & $0.47^{*}$ & $0.94^{*}$ & $0.93^{*}$ \\
Total body fat & $0.96^{*}$ & $0.56^{*}$ & $0.95^{*}$ & $0.94^{*}$ & $0.94^{*}$ & $0.46^{*}$ & $0.93^{*}$ & $0.95^{*}$ \\
\hline
\end{tabular}

WC, waist circumference; WHR, waist-to-hip ratio; WHtR, waist-to-height ratio; Trunk SKF, subscapular + suprailiac + abdominal skinfold; BMI, body mass index; ${ }^{*} \mathrm{p}=0.01$.

Table 3. Multiple linear regression analysis to predict central body fat distribution of Thai preschool children.

\begin{tabular}{|c|c|c|c|c|c|c|c|c|c|}
\hline \multirow[t]{2}{*}{ Outcome variables } & \multicolumn{4}{|c|}{ Boys $(n=406)$} & \multirow[t]{2}{*}{ Outcome variables } & \multicolumn{4}{|c|}{ Girls $(n=405)$} \\
\hline & B & SE & $\mathbf{P}$ & Adjusted $\mathbf{R}^{2}$ & & B & SE & $\mathbf{P}$ & Adjusted $\mathbf{R}^{2}$ \\
\hline Waist circumference & & & & 0.931 & Waist circumference & & & & 0.921 \\
\hline Constant & 16.101 & 2.524 & 0.0001 & & Constant & 11.782 & 2.257 & 0.0001 & \\
\hline BMI & 1.703 & 0.172 & 0.0001 & & BMI & 1.985 & 0.146 & 0.0001 & \\
\hline Total body fat & 0.304 & 0.060 & 0.0001 & & Age & 1.309 & 0.294 & 0.0001 & \\
\hline Age & 1.127 & 0.276 & 0.0001 & & Total body fat & 0.238 & 0.065 & 0.0001 & \\
\hline Waist-to-hip ratio & & & & 0.314 & Waist-to-hip ratio & & & & 0.217 \\
\hline Constant & 0.965 & 0.026 & 0.0001 & & Constant & 0.835 & 0.010 & 0.0001 & \\
\hline Total body fat & 0.003 & 0.000 & 0.0001 & & BMI & 0.006 & 0.001 & 0.0001 & \\
\hline Age & -0.011 & 0.005 & 0.023 & & & & & & \\
\hline Waist-to-height ratio & & & & 0.916 & Waist-to-height ratio & & & & 0.903 \\
\hline Constant & 0.327 & 0.021 & 0.0001 & & Constant & 0.330 & 0.017 & 0.0001 & \\
\hline BMI & 0.011 & 0.001 & 0.0001 & & BMI & 0.012 & 0.001 & 0.0001 & \\
\hline Total body fat & 0.003 & 0.000 & 0.0001 & & Age & -0.013 & 0.002 & 0.0001 & \\
\hline Age & -0.010 & 0.002 & 0.0001 & & Total body fat & 0.002 & 0.000 & 0.0001 & \\
\hline Trunk skinfolds & & & & 0.877 & Trunk skinfolds & & & & 0.898 \\
\hline Constant & -12.757 & 4.298 & 0.003 & & Constant & -13.202 & 2.521 & 0.0001 & \\
\hline Total body fat & 1.079 & 0.131 & 0.0001 & & Total body fat & 1.343 & 0.114 & 0.0001 & \\
\hline BMI & 1.059 & 0.376 & 0.005 & & BMI & 0.942 & 0.258 & 0.0001 & \\
\hline
\end{tabular}

BMI, body mass index; Trunk skinfolds, subscapular + suprailiac + abdominal skinfolds.

positive correlation between WC and BMI $(r=0.90$ 0.94) among Japanese school children [30,31] although study by Wang et al. [32], in Chinese children aged 6-11 years, found that WC was slightly correlated with TBF ( $\mathrm{r}$ $=0.27-0.36)$ as measured by DXA. Regarding WHtR, our results indicated that child's age was one determinant factor of WHtR value in both genders. Generally, WHtR value was found to be relatively constant with age. $[23,33]$. The use of WHtR for nutritional assessment provides the advantage in that the index allows the same 
boundary value for various age group of children as well as for different ethnic group [34] and evidence showed that WHtR index was associated with high metabolic risk $[35,36]$. The finding of association between WHtR and TBF in our study deserved be further investigated in young children. Our results also revealed that TBF and BMI were associated with trunk skinfolds of children. This was according to the former study which showed that total fat mass is an important determinant factor of intra-abdominal adipose tissue (IAAT) and abdominal skinfold was strongly correlated with IAAT [37]. In addition, skinfold thickness at a varying anatomical sites was used to address gender and ethnic variation related to subcutaneous fat distribution [6]. However, our results showed the weak association between WHR and TBF in boys and between WHR and BMI in girls which implied that WHR was less sensitive index than WC, WHtR and trunk skinfold for this age group. Goran et al. [38] demonstrated that, in young children, WHR was not significantly correlated with intra-abdominal adipose tissue (IAAT) while trunk skinfold thickness could explain 62\% of variation in IAAT and that WC could explain 92\% of the variation in subcutaneous abdominal adipose tissue (SAAT) [37]. Hence, the combination of skinfolds and waist circumference measurement could help to predict central adiposity in the absence of direct measurement by computed tomography or magnetic resonance imaging technique. The limitation of our study was that we did not directly measure the IAAT of children, thereby, this might affect the extensive interpretation of the results of study.

In summary, the assessment of central body fat distribution in children can be done using various anthropometric indices. Our study showed that there was no difference in central body fat indices between young Thai boys and girls. Change in body fat distribution could be affected by the age, BMI and TBF of children. Further study needs to investigate the relationship of various body fat distribution indices to adverse biochemical parameters among young children.

\section{ACKNOWLEDGEMENTS}

We gratefully acknowledge funding from Takeda Science Foundation. We thanks all parents and children in Saraburi province for their participation in the study. We also thank Ms Weeraya Karnpanit, Ms Kittirat Wongin and Mr. Chumlong Sangmueang for their assistance in data collection.

\section{REFERENCES}

[1] Dehghan, M., Akhtar-Danesh, N. and Merchant, A.T. (2005) Childhood obesity, prevalence and prevention. Journal of Nutrition, 4, 24-31. doi:10.1186/1475-2891-4-24
[2] Kipping, R.R., Jago, R. and Lawlor, D.A. (2008) Obesity in children. Part I: Epidemiology, measurement, risk factors and screening. British Medical Journal, 337, 922927. doi:10.1136/bmj.a1824

[3] Must, A. and Anderson, S.E. (2006) Body mass index in children and adolescents: Considerations for populationbased applications. International Journal of Obesity, 30, 590-594. doi:10.1038/sj.ijo.0803300

[4] Teixeira, P.J., Sardinha, L.B., Going, S.B. and Lohman, T.G. (2001) Total and regional fat and serum cardiovascular disease risk factors in lean and obese children and adolescents. Obesity Research, 9, 432-442. doi:10.1038/oby.2001.57

[5] Caprio, S., Hyman, L.D., McCarthy, S., et al. (1996) Fat distribution and cardiovascular risk factors in obese adolescent girls: Importance of the intra-abdominal fat depot. American Journal of Clinical Nutrition, 64, 12-17.

[6] Malina, R.M. (1996) Regional body composition: Age, sex and ethnic variation. In: Roche, A.F., Heymsfield, S.B. and Lohman, T.G., Eds., Human Body Composition, Human Kinetics, Champaign, 217-256.

[7] Rolland-Cachera, M.F., Bellisle, F., Deheeger, M., Pequignot, F. and Sempe, M. (1990) Influence of body fat distribution during childhood on body fat distribution in adulthood: A two-decade follow-up study. International Journal of Obesity, 14, 473-481.

[8] Westrate, J.A., Deurenberg, P. and Van Tinteren, H. (1989) Indices of body fat distribution and adiposity in Dutch children from birth to 18 years of age. International Journal of Obesity, 13, 465-477.

[9] Mast, M., Kortzinger, I., Konig, E. and Muller, M.J. (1998) Gender differences in fat mass of 5-7 year old children. International Journal of Obesity, 22, 878-884. doi:10.1038/sj.ijo.0800675

[10] Yanovski, J.A., Yanovski, S.Z., Filmer, K.M., et al. (1996) Differences in body composition of black and white girls. American Journal of Clinical Nutrition, 64, 833-839.

[11] He, Q., Horlick, M., Thornton, J., Jack, W., Pierson, R.N., Heshka, S., et al. (2002) Sex and race difference in fat distribution among Asian, African-American and Caucasian prepubertal children. Journal of Clinical Endocrinology \& Metabolism, 87, 2164-2170. doi:10.1210/jc.87.5.2164

[12] Liu, A., Byrne, N.M., Kagawa, M., et al. (2011) Ethnic differences in body fat distribution among Asian pre-pubertal children. A cross-sectional multicenter study. BMC Public Health, 11, 500-507. doi:10.1186/1471-2458-11-500

[13] Malina, R.M., Huang, Y.-C. and Brown, K.H. (1995) Subcutaneous adipose tissue distribution in adolescent girls of four ethnic groups. International Journal of Obesity, 19, 793-797.

[14] Daniels, S.R., Khoury, P.R. and Morrison, J.A. (2000) Utility of different measures of body fat distribution in children and adolescents. American Journal of Epidemiology, 152, 1179-1184. doi:10.1093/aje/152.12.1179

[15] Garnett, S.P., Baur, L.A. and Cowell, C.T. (2008) Waistto-height ratio: A simple option for determining excess 
central adiposity in young people. International Journal of Obesity, 32, 1028-1030. doi:10.1038/ijo.2008.51

[16] Moreno, L.A., Fleta, J., Mur, L., Sarria, A. and Bueno, M. (1998) Fat distribution in obese and non-obese children and adolescents. Journal of Pediatric Gastroenterology and Nutrition, 27, 176-180.

doi:10.1097/00005176-199808000-00009

[17] Katzmarzyk, P.T., Srinivasan, S.R., Chen, W., et al. (2004) Body mass index, waist circumference and clustering of cardiovascular disease risk factors in a biracial sample of children and adolescents. Pediatrics, 114, e198-e205. doi:10.1542/peds.114.2.e198

[18] Savva, S.C., Tornaritis, M., Savva, M.E., et al. (2000) Waist circumference and waist-to-height ratio are better predictors of cardiovascular disease risk factors in children than body mass index. International Journal of Obesity, 24, 1453-1458. doi:10.1038/sj.ijo.0801401

[19] Brambilla, P., Bedogni, G., Moreno, L.A., et al. (2006) Cross validation of anthropometry against magnetic resonance imaging for the assessment of visceral and subcutaneous adipose tissue in children. International Journal of Obesity, 30, 23-30.

doi:10.1038/sj.ijo.0803163

[20] Asayama, K., Hayashibe, H., Dobashi, K., et al. (1995) Relationships between biochemical abnormalities and anthropometric indices of overweight, adiposity and body fat distribution in Japanese elementary school children. International Journal of Obesity, 19, 253-259.

[21] Aekplakorn, W., Satheannoppakao, W. and Preunglumpoo, S. (2009) The fourth national health examination survey, 2008-2009. Final Report, National Health Examination Survey Office, Bangkok.

[22] McCarthy, H.D., Jarrett, K.V. and Crawley, H.F. (2001) The development of waist circumference percentiles in British children aged 5.0-16.9 y. European Journal of Clinical Nutrition, 55, 902-907. doi:10.1038/sj.ejen.1601240

[23] Sung, R.Y.T., So, H.-K., Choi, K.C., et al. (2008) Waist circumference and waist-to-height ratio of Hong Kong Chinese children. BMC Public Health, 8, 324-333. doi:10.1186/1471-2458-8-324

[24] Webster-Gandy, J., Warren, J. and Henry, C.J.K. (2003) Sexual dimorphism in fat patterning in a sample of 5 to 7 -year-old children in Oxford. International Journal of Food Sciences and Nutrition, 54, 467-471.

[25] Malina, R.M., Bouchard, C. and Beunen, G. (1988) Human growth: Selected aspects of current research on well nourished children. Annual Review of Anthropology, 17, 187-219. doi:10.1146/annurev.an.17.100188.001155

[26] Garnett, S.P., Hogler, W., Blades, B., et al. (2004) Relation between hormones and body composition, including bone, in prepubertal children. American Journal of Clinical Nutrition, 80, 966-972.

[27] Taylor, R.W., Grant, A.M., Williams, S.M. and Goulding, A. (2010) Sex differences on regional body fat distribution from pre- to postpuberty. Obesity, 18, 1410-1416.

\section{doi:10.1038/oby.2009.399}

[28] Glaber, N., Zellner, K. and Kromeyer-Hauschild, K. (2011) Validity of body mass index and waist circumference to detect excess fat mass in children 7-14 years. European Journal of Clinical Nutrition, 65, 151-159. doi:10.1038/ejcn.2010.245

[29] Hubert, H., Guinhouya, C.B., Allard, L. and Durocher, A. (2009) Comparison of the diagnostic quality of body mass index, waist circumference and waist-to-height ratio in screening skinfold-determined obesity among children. Journal of Sports Science and Medicine, 12, 449-451. doi:10.1016/j.jsams.2008.05.002

[30] Ochiai, H., Shirasawa, T., Nishimura, R., et al. (2010) Relationship of body mass index to percent body fat and waist circumference among school children in JapanThe influence of gender and obesity: A population-based cross-sectional study. BMC Public Health, 10, 493-498. doi:10.1186/1471-2458-10-493

[31] Morimoto, A., Nishimura, R., Kanda, A., et al. (2007) Waist circumference estimation from BMI in Japan children. Diabetes Research and Clinical Practice, 75, 96-98. doi:10.1016/j.diabres.2006.05.022

[32] Wang, H., Story, R.E., Venners, S.A., et al. (2007) Patterns and interrelationships of body-fat measures among rural Chinese children aged 6-18 years. Pediatrics, 120, e94-e101. doi:10.1542/peds.2006-2114

[33] Aeberli, I., Gut-Knabenhans, M., Kusche-Amman, R.S., Molinari, L. and Zimmermann, M.B. (2011) Waist circumference and waist-to-height ratio percentiles in a nationally representative sample of 6-13 year old children in Switzerland. Swiss Medical Weekly, 141, w13227-w13232.

[34] Ashwell, M. and Hsieh, S.D. (2005) Six reasons why the waist-to-height ratio is rapid and effective global indicator for health risks of obesity and how its use could simplify the international public health message on obesity. International Journal of Food Sciences and Nutrition, 56, 303-307. doi:10.1080/09637480500195066

[35] Maffeis, C., Banzato, C. and Talamini, G. (2008) Waistto-height ratio, a useful index to identify high metabolic risk in overweight children. Journal of Pediatrics, 152, 207-213. doi:10.1016/j.jpeds.2007.09.021

[36] Freedman, D.S., Khan, H.S., Mei, Z., et al. (2007) Relation of body mass index and waist-to-height ratio to cardiovascular disease risk factors in children and adolescents: The Bogalusa heart study. American Journal of Clinical Nutrition, 86, 33-40.

[37] Goran, M.I., Gower, B.A., Treuth, M.T. and Nagy, T.R. (1998) Prediction of intra-abdominal and subcutaneous abdominal adipose tissue in healthy prepubertal children. International Journal of Obesity, 22, 549-558. doi:10.1038/sj.ijo.0800624

[38] Goran, M.I., Kaskoun, M.C. and Shuman, W.P. (1995) Intra-abdominal adipose tissue in young children. International Journal of Obesity, 19, 279-283. 